\title{
Radial Basis Function Neural Network with Particle Swarm Optimization Algorithms for Regional Logistics Demand Prediction
}

\author{
Zhineng Hu, Yixin Zhang, and Liming Yao \\ Uncertainty Decision-Making Laboratory, Sichuan University, Chengdu 610064, China \\ Correspondence should be addressed to Liming Yao; lmyao@scu.edu.cn
}

Received 26 June 2014; Revised 8 September 2014; Accepted 4 November 2014; Published 26 November 2014

Academic Editor: Zhigang Jiang

Copyright (C) 2014 Zhineng Hu et al. This is an open access article distributed under the Creative Commons Attribution License, which permits unrestricted use, distribution, and reproduction in any medium, provided the original work is properly cited.

\begin{abstract}
Regional logistics prediction is the key step in regional logistics planning and logistics resources rationalization. Since regional economy is the inherent and determinative factor of regional logistics demand, it is feasible to forecast regional logistics demand by investigating economic indicators which can accelerate the harmonious development of regional logistics industry and regional economy. In this paper, the PSO-RBFNN model, a radial basis function neural network (RBFNN) combined with particle swarm optimization (PSO) algorithm, is studied. The PSO-RBFNN model is trained by indicators data in a region to predict the regional logistics demand. And the corresponding results indicate the model's applicability and potential advantages.
\end{abstract}

\section{Introduction}

With the rapid economic development and the continuous advancement of information and technology, modern logistics industry is developing fast on a global scale. Therefore, logistics industry is considered to be the foundation as well as the basic industry of national economic development. Meanwhile, its level of development becomes an essential symbol of measuring a country's modernization and comprehensive economic strength.

Regional logistics demand prediction system is a crucial part of regional logistics system planning and logistics rational allocation process of resources. This is because the regional logistics demand prediction system provides the necessary basis for decision making of the government. It also provides support for the construction of logistics infrastructure. Scholars at home and around the world established more predictive models for macrologistics needs, for example, the space-time multinomial probity model of forecasting freight transportation [1], nonlinear air services demand model based on time series [2], stepwise linear regression method for cargo forecasting [3], logistics demand analysis model combining input-output and spatial price [4], route comparison model and gravity model [5], grey prediction model, fuzzy forecast and neural network prediction model, and so forth [6-8]. Yet, few scholars combined regional economic development with regional logistics demand forecasts closely together. The vast majority of the literature focused on using historical data of logistics needs for logistics demand forecasting, rather than utilizing economic data to forecast demand for logistics.

Many domestic and foreign scholars have conducted researches on the prediction of regional logistics demand. It is basically divided into two categories: time series prediction method and causality prediction method. Time series prediction method is a kind of approach based on the evolution rules of the predicted object, which are found out from the historical data of the time series. Commonly used models include moving average, exponential smoothing, and grey model. Causality prediction method is to infer the developing trend of things by establishing the appropriate causality forecasting model, based on the relationship between variables of prediction object and variables of its related things found out from historical data, and using the causal relationship of things development. Commonly used models include elastic coefficient method, linear regression model, and artificial neural network model. Commonly used prediction methods and the applicable situation are shown in Table 1. 
TABLE 1: Common forecasting methods.

\begin{tabular}{|c|c|}
\hline Forecasting methods & The applicable situation \\
\hline Moving average [24] & Suitable for spot prediction \\
\hline $\begin{array}{l}\text { Exponential } \\
\text { smoothing [25] }\end{array}$ & $\begin{array}{l}\text { Repeated prediction with or without a } \\
\text { change in seasons }\end{array}$ \\
\hline Grey model [6] & $\begin{array}{l}\text { Development of time series showing } \\
\text { exponential trend }\end{array}$ \\
\hline $\begin{array}{l}\text { Elastic coefficient } \\
\text { method }[26]\end{array}$ & $\begin{array}{l}\text { Two factors between } X \text { and } Y \text { have an } \\
\text { exponential relationship }\end{array}$ \\
\hline $\begin{array}{l}\text { Linear regression } \\
\text { model }[3]\end{array}$ & $\begin{array}{l}\text { A linear relationship between } \\
\text { independent variables and dependent } \\
\text { variables }\end{array}$ \\
\hline $\begin{array}{l}\text { Artificial neural } \\
\text { network model [7] }\end{array}$ & $\begin{array}{l}\text { Being able to make prediction of } \\
\text { nonlinear corresponding relationship }\end{array}$ \\
\hline
\end{tabular}

Time series forecasting method does not consider the influence of other economic development indicators. It disregards that the regional logistics demand is of derivation. Hence, there are often serious prediction errors. On the other hand, compared with the macrologistics, regional logistics demand prediction has its own characteristics: there exists a high degree of nonlinearity between logistics demand and the impact of logistics demand indicators, as well as greater volatility than macrologistics. Due to these features, the traditional time series forecasting methods (such as grey model) and linear prediction methods (such as linear regression model) do not work effectively. Consequently, artificial neural network (ANN) model is more suitable. Furthermore, it is exactly the complexity and nonlinearity of regional logistics demand system that make a single prediction model function not well [9-12]. Therefore it is necessary to use a combined model.

In this paper, a regional logistics demand prediction index system with economic indicators and logistics indicators and a regional logistics demand prediction model based on radial basis function neural network (RBFNN) combined with particle swarm optimization (PSO) algorithm will be built. The PSO-RBFNN model will be trained with processed data from Sichuan province and will be applied to predict the regional logistics demand in the very area as well. The prediction result will be evaluated and compared with a backpropagation (BP) neural network and regular RBFNN. Eventually, the results and conclusions drawn from the PSORBFNN prediction model will be discussed and summarized.

\section{Problem Description}

2.1. Problem Background. In order to enhance the investment environment, to increase the attraction of foreign investment, to solve the employment pressure, and to improve the comprehensive competitiveness of urban areas, multiple regions in China have adopted a variety of planning policies to encourage the development of logistics and construction of logistics infrastructure. Nonetheless, China's logistics started late, and the related policies, strategies, and planning are not mature. Planners' understanding of the development of modern logistics concept and mode of operation is still not unified, especially in the field of logistics demand and so on. When formulating logistics development policies and studying the feasibility of logistics infrastructure, scholars ascertain that the lack of quantitative data about logistics demand results in numerous problems in the planning process, for instance, the imbalance between actual supply capacity of logistics and logistics demand, repeated construction and sedimentation of money caused by tremendous waste of resources, and false prosperity of logistics industry. Overall, predicting regional logistics demand is critical for the sustainable development of regional logistics industry.

Therefore, the quantitative prediction of the scale and development trends of logistics demand is essential. To begin with, this kind of predictions can purposefully guide social investment into the field of logistics. Various types of logistics infrastructure can be rationally planned and constructed; logistics supply system and network layout can be improved. Moreover, the predictions continuously provide the basis for the supply to meet the demand, so as to maintain a relative balance between supply and demand for logistics services and to make the regional logistics maintain high efficiency.

2.2. Related Concepts of Regional Logistics Demand. Currently, there is no uniform view for the definition of regional logistics. Dong [13] holds that regional logistics is a system aiming at optimizing the socioeconomic strategies through the planning and construction of a certain region. Meanwhile, it also refers to activities associated with logistics operation and control. In accordance with the systems defined by systems engineering, the regional logistics system can be defined as follows: in a certain economic geographic area, it is an organic whole with specific operating law and function formed by interrelated, interdependent, and interacting elements of all logistics at different spatial scales. The regional logistics system is illustrated in Figure 1.

Compared with the national logistics systems and enterprise logistics system, the regional logistics system is an organic integrated logistics system within the range of the economic region. The basic structural unit of the regional logistics system is a microenterprise supply, sales, logistics, and so on. Meanwhile, it is a vital part of the national logistics, international logistics, and other macrologistics systems. The regional logistics system, which is mesolevel, becomes the convergence of the microscopic and macroscopic logistics systems. Its purpose is to apply the logistics chain management solutions to address a variety of logistical problems beyond a single enterprise, so as to achieve logistics rationalization in a region or in a wider range of areas [14-16], as is indicated in Figure 2.

Logistics demand prediction is based on the relationship between past and current logistics market demand information and factors affecting the changes in the logistics market demand. It uses sound judgment experience, technical methods, and predictive models on the basis of historical data and statistical information to derive some regularity trends and intrinsic link trends among the factors, which predicts indicators reflecting market demand trends. Logistics demand prediction is preestimates and predictions 


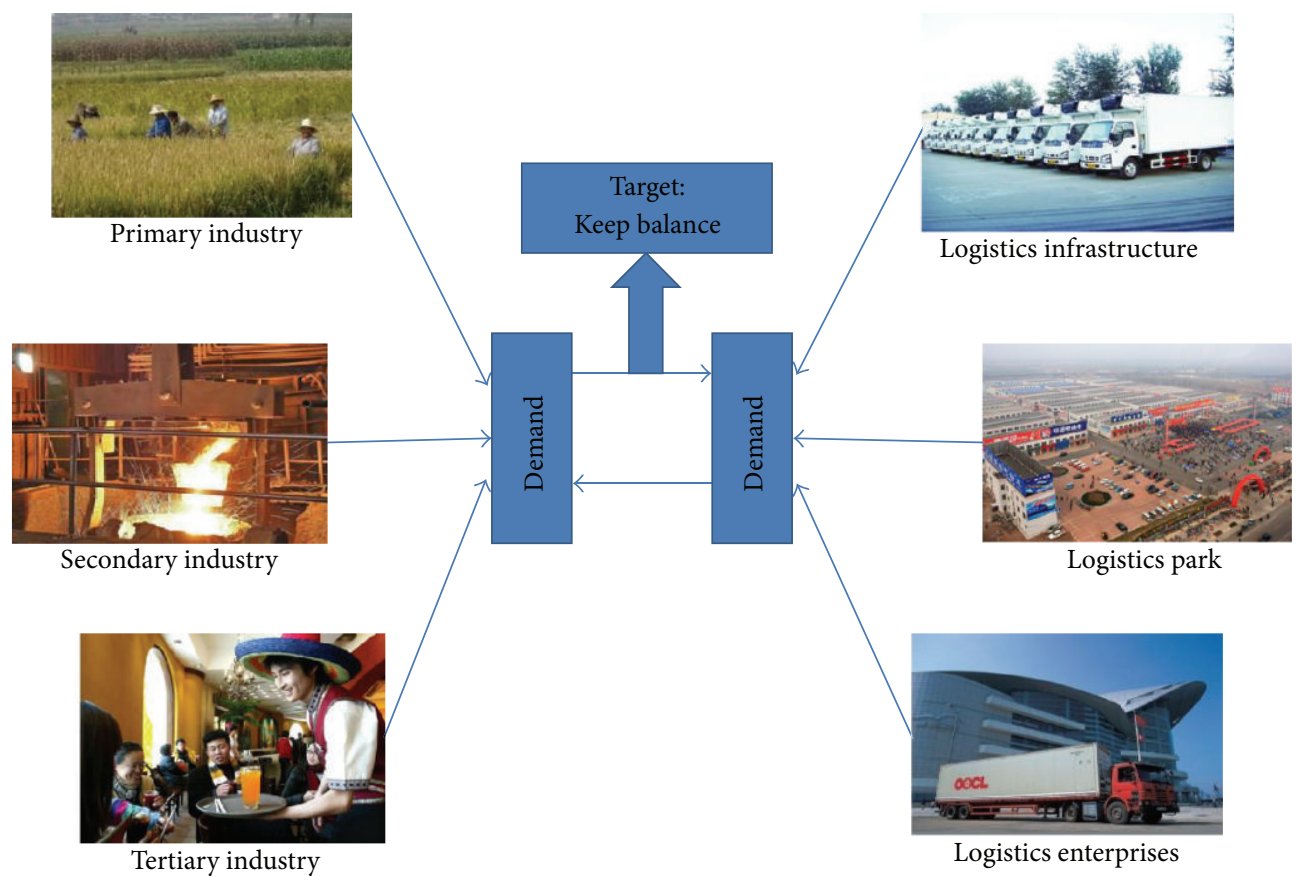

FIGURE 1: The regional logistics system.

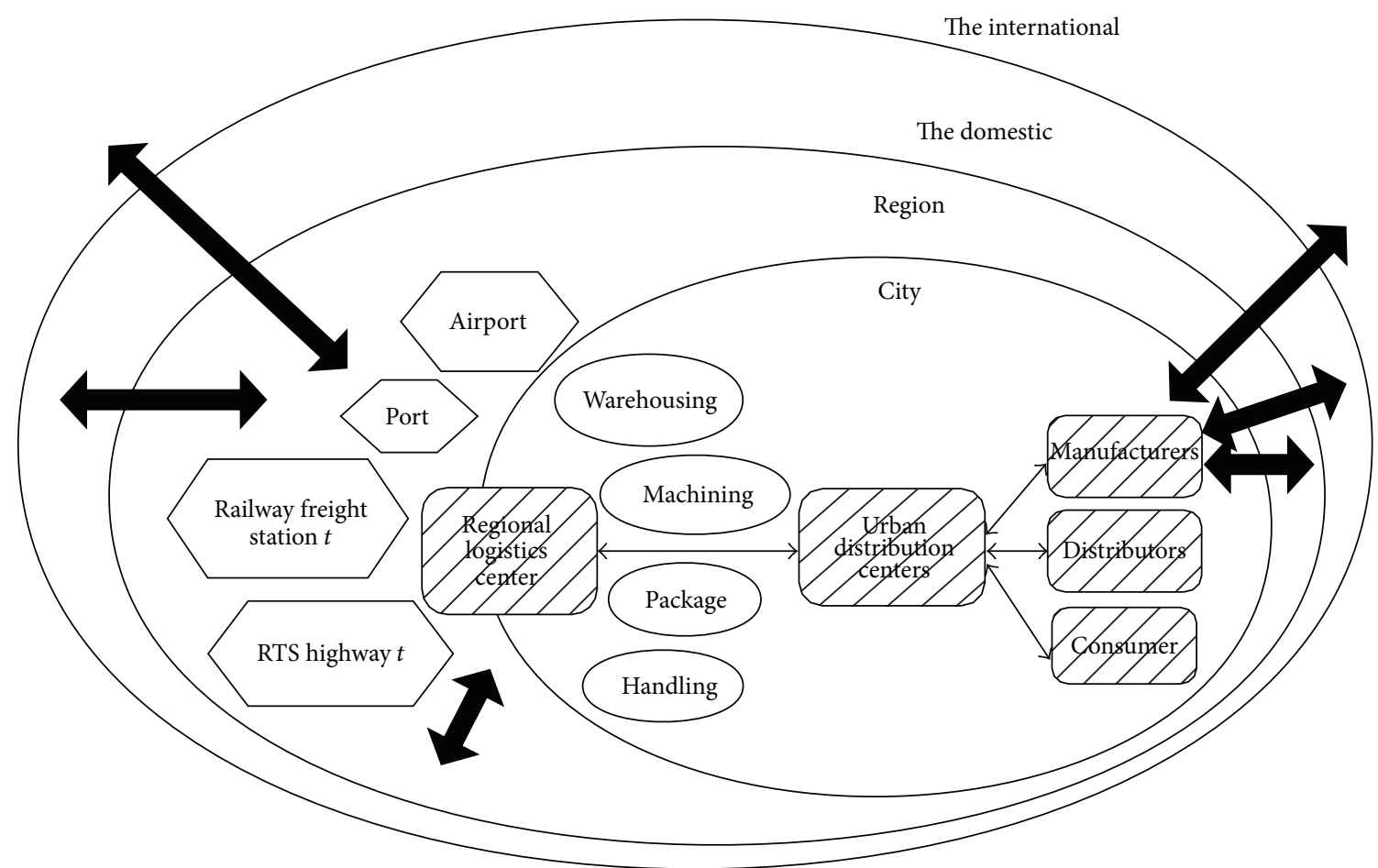

FIGURE 2: Internal structure of regional logistics system.

of the cargo traffic, source, flow, velocity, and other goods constituting in the area which have not occurred or is not yet clear, so as to meet the scale of regional logistics demand and hierarchy of needs. Finally, it provides decision-making basis for the regional logistics planning.

\section{Methodologies}

Before modeling, we select suitable regional logistics demand prediction indicators, thereby keeping accuracy and reliability of regional logistics demand prediction. 
3.1. Selecting the Regional Logistics Demand Indicators. The regional logistics demand scale indicator is the most important indicator in regional logistics demand indicators. It reflects the development of the logistics industry and the supply of logistics services in the region, namely, the size and level of total demand for logistics. It is also the most significant data the government and corporate decisionmakers should first master. Generally, scale indicators of regional logistics demand can be set from several different angles, as demonstrated in Table 2.

According to the logistic current situation and the principle of regional logistic prediction indicators, we select total freight traffic (TFT, $y_{1}, 10000$ tons) and freight turnover (FT, $y_{2}, 100$ million ton- $\mathrm{km}$ ) as the prediction targets.

Regional economic indicators are the economic indicators utilized in the prediction and have tremendous impacts on regional logistics demand. The total regional economy, regional economic structure, and distribution are major economic factors impacting regional logistics demand. In addition, intraregional trade, regional income per capita, and consumption level are also important influencing factors. Hence, when setting regional economic indicators, we select as many related indicators as we can to make prediction more effective. Meanwhile, we have to consider that indicators' data should be relatively easy to obtain from the regional statistical yearbook. Regional economic indicators are set using the measures illustrated in Table 3.

\subsection{Building Regional Logistics Demand Prediction Index} System. Combined with the previous analysis and taking into account the availability of statistical data limits, in this research we select total freight traffic (TFT, $y_{1}, 10000$ tons) and freight turnover (FT, $y_{2}, 100$ million ton-km) to measure the scale of regional logistics demand. Likewise, we select gross domestic product (GDP, $x_{1}$, billion yuan), primary industry output value (PIO, $x_{2}$, billion yuan), secondary industry output value (SIO, $x_{3}$, billion yuan), tertiary industry output value (TIO, $x_{4}$, billion yuan), regional retail sales (RRS, $x_{5}$, million yuan), total import and export (TIE, $x_{6}$, million dollar), and per capita consumption (PCC, $x_{7}$, yuan per person) as economic indicators to predict the regional logistics demand. These indicators of input and output will be utilized to train the PSO-RBFNN and predict the regional logistics demand. The index system predicting regional logistics demand is exhibited in Figure 3.

\subsection{The Radial Basis Function Neural Network (RBFNN). The} artificial neural network (ANN) is a nonlinear information processing system which imitates human brain structure and function. According to the potential law, ANN is able to extrapolate new output by using new input. Hence, ANN has the ability to adapt to the changing environment and to achieve real value mapping of any complex functions. ANN is widely utilized to resolve problems such as pattern recognition, forecasting and prediction, optimization control, and intelligent decision-making. The feedforward neural networks are one of the most widely used ANNs. Backpropagation (BP) network, radial basis function neural network
TABLE 2: Regional logistics demand indicators.

\begin{tabular}{lll}
\hline $\begin{array}{l}\text { Indicator } \\
\text { species }\end{array}$ & $\begin{array}{l}\text { Classification } \\
\text { standards }\end{array}$ & Setting indicators \\
\hline Freight scale & $\begin{array}{l}\text { Volume of freight traffic } \\
\text { and freight turnover }\end{array}$ \\
$\begin{array}{l}\text { Indicators of } \\
\text { logistics } \\
\text { demand scale }\end{array}$ & Logistics costs logistics costs and the \\
& $\begin{array}{l}\text { Investment in } \\
\text { fixed assets } \\
\text { in GDP } \\
\text { Total investment in } \\
\text { logistics fixed assets } \\
\text { The proportion of the } \\
\text { number of employes in } \\
\text { total employment or total } \\
\text { population }\end{array}$ \\
\hline
\end{tabular}

TABLE 3: Logistics demand forecast economic indicators.

\begin{tabular}{ll}
\hline Indicator species & Setting indicators \\
\hline Indicators of economic scale & $\begin{array}{l}\text { Gross domestic product (GDP) } \\
\text { and GDP per capita } \\
\text { Primary industry output value, } \\
\text { secondary industry output value, } \\
\text { andicators of industrial } \\
\text { structure }\end{array}$ \\
$\begin{array}{l}\text { value } \\
\text { Regional retail sales and total } \\
\text { volume of regional foreign trade } \\
\text { Indicators of household } \\
\text { consumption level }\end{array}$ & $\begin{array}{l}\text { Consumption level per capita } \\
\text { and income per capita }\end{array}$ \\
\hline
\end{tabular}

(RBFNN), and group method of data handling (GMDH) network are the typical feedforward neural networks.

The radial basis function neural network (RBFNN) was proposed by Moody and Darken [17]. It is a commonly used FNN with only one hidden layer. A RBFNN consists of three layers: the input layer, the hidden layer, and the output layer. The transformation from the input layer to the hidden layer is nonlinear. The output layer is linear and gives a summation at the output units. The architecture of RBFNN is illustrated in Figure 4, where $n$ input units, $h$ hidden units, and $m$ output units are in the RBFNN. $\mathbf{x}=$ $\left[x_{1}, x_{2}, \ldots, x_{n}\right]^{T} \in \mathbf{R}^{n}$ is the input vector, $\mathbf{W}=\mathbf{R}^{h \times m}$ is the output weight matrix, $b_{1}, \ldots, b_{m}$ are the output units migration, $\mathbf{y}=\left[y_{1}, y_{2}, \ldots, y_{m}\right]^{T}$ is the output vector. $\Phi_{i}\left(\left\|x-c_{i}\right\|\right)$ is $i$ th hidden unit's activation function. $\sum$ in the output unit indicates that the output layer neurons use linear activation function. As a result, the $k$ th output can be represented as $y_{k}=\sum_{i=1}^{h} w_{i} \Phi_{i}\left(\left\|x-c_{i}\right\|\right)$, where $w_{i}$ denotes the connection weight with which decision makers endow the radial basis function.

The essential feature of the RBFNN is that it utilizes the distance (Euclidean distance) function as the basis function and the radial basis function (such as Gaussian function) as activation functions. The radial basis function is a radial 


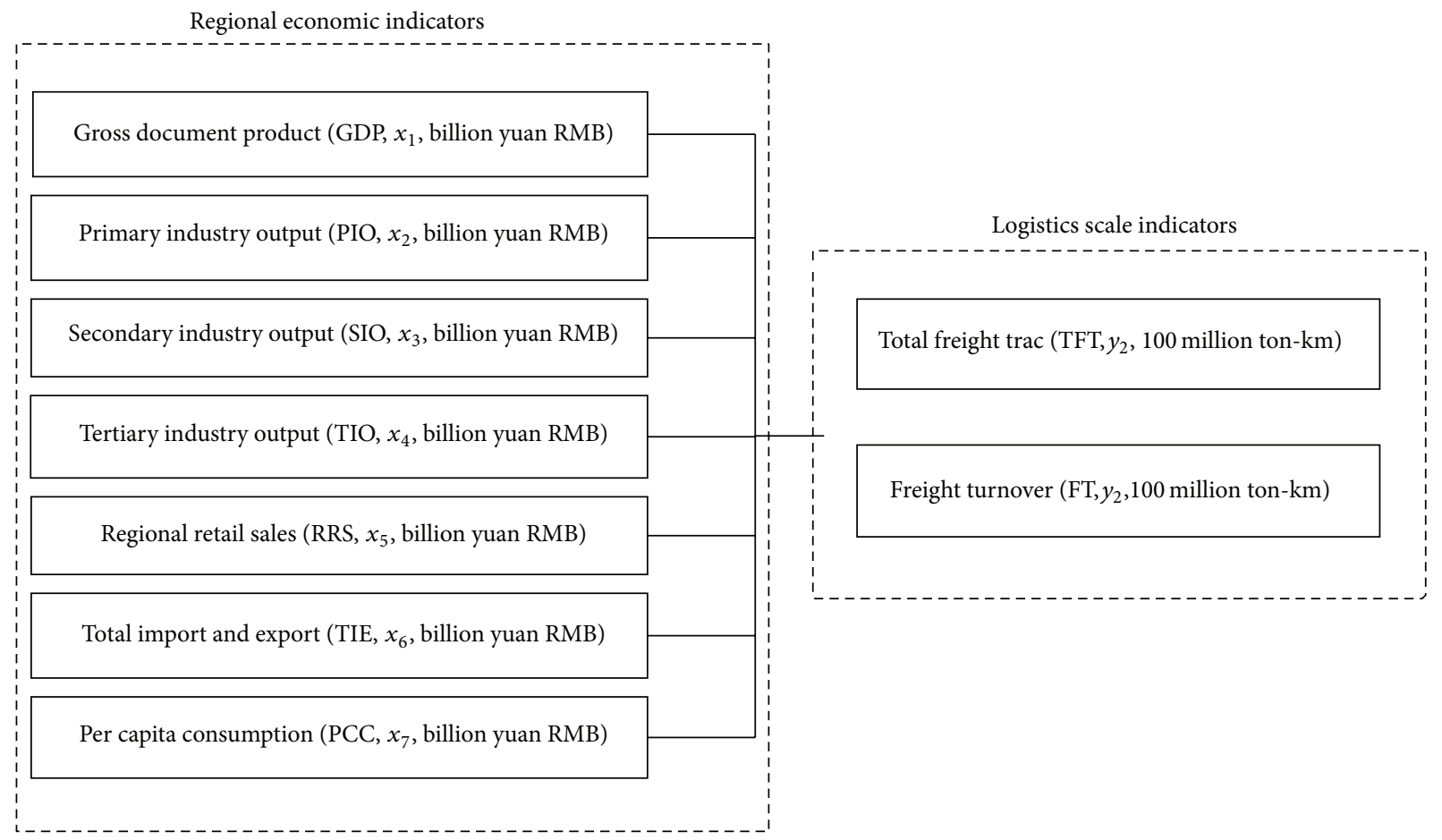

FIGURE 3: Regional logistics demand prediction index system.

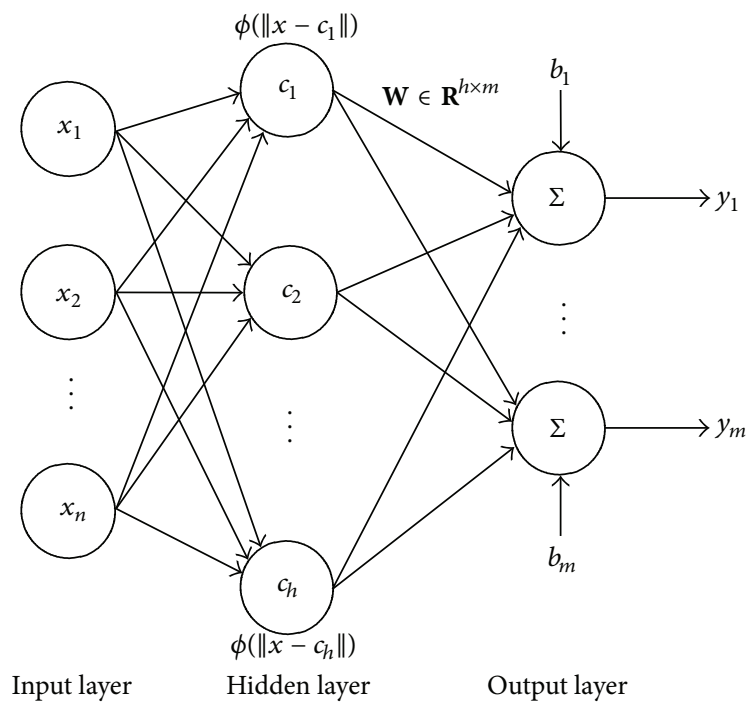

FIGURE 4: The architecture of RBFNN.

symmetry about a center point in $N$-dimension space. The farther the input neurons are away from the center point, the lower the level of the neuron activation is. This characteristic of hidden units is called "local quality." Therefore each hidden unit has a center point. As is shown in Figure $4, c_{i}$ is the center point value of the $i$ th hidden unit; $\left\|x-c_{i}\right\|$ is the Euclidean norm which indicates the distance from $x$ to $c_{i}$. The radial basis function $\Phi_{i}(\cdot)$ has various forms, which are commonly used as follows, where $\delta_{i}$ is called the spread of the basis function [18]:

$$
\begin{aligned}
& \Phi_{i}(t)=e^{-\left(t^{2} / \delta_{i}^{2}\right)}, \quad \text { Gaussian function } \\
& \Phi_{i}(t)=\frac{1}{1+e^{t^{2} / \delta^{2}}}, \quad \text { reflected sigmoid function } \\
& \Phi_{i}(t)=\frac{1}{\left(t^{2}+\delta_{i}^{2}\right)^{\alpha}}, \quad \alpha>0,
\end{aligned}
$$

inverse multiquadric function.

Like the human brain's neural network, RBFNN's functions are obtained through continuous learning. As the property of the neural network depends on network topology and connection weights between nodes, and the topological structure is often chosen according to specific applications, the RBFNN learning problem is to adjust the connection weights between nodes. Weights can be determined by two methods: (a) determined when RBFNN is designed; (b) determined by learning (or training) according to certain rules. Overall, the latter is mainly applied because the RBFNN obtained by learning has better adaptability. RBFNN's topology and basis function have some advantages.

(1) RBFNN has a good capability to approximate any nonlinear mapping and processing system's inherent regularity which is difficult to express. For noise-free data, RBFNN has better fitting capability and higher prediction accuracy. For data with noise, RBFNN's fitting error and prediction error are smaller, and the 
convergence rate is faster than other neural networks, such as BP neural network.

(2) RBFNN topology can not only improve the learning speed but also avoid the local minimum. In addition, RBFNN's transfer function adopts radial basis functions, particularly the Gaussian function. As the Gaussian function has a simple representation, so even a multivariable input would not add much complexity. And it is easy to theoretically analyse.

(3) RBFNN has a self-learning, self-organizing, selfadaptive capability, and a fast learning speed. RBFNN can achieve a wide range of data fusion and data parallel processing at high speed.

3.4. The Particle Swarm Optimization Algorithm. The particle swarm optimization (PSO) algorithm is an evolutionary technique first proposed by Kennedy and Eberhart [19] and inspired by the natural flocking and swarming behavior of birds and insects [20]. The PSO algorithm works through initializing a swarm randomly in the search space, attracting the particles to search for space positions of high fitness. Each particle has an adaptive value determined by the optimized function. The velocity of each particle will determine its direction and distance, and the particles will follow the optimal particle searching in the searching space [21].

Evolutionary algorithm is varied. Generalized evolutionary algorithm includes genetic algorithms, particle swarm optimization, and ant colony algorithm, in which genetic algorithm and particle swarm algorithm are most typical. In comparison with other evolutionary algorithms such as genetic algorithm, PSO algorithm has the following advantages: (a) the algorithm is simple and easy to implement; (b) computation amount of the algorithm is small; (c) the computational efficiency of the algorithm is high.

3.4.1. The Principle of PSO. Suppose in $N$-dimensional searching space, a swarm consisting of $m$ particles is $\mathbf{X}=$ $\left(x_{1}, x_{2}, \ldots, x_{i}, \ldots, x_{m}\right)$, where the position of the $i$ th particle is $x_{i}=\left(x_{i 1}, x_{i 2}, \ldots, x_{i n}\right)^{T}$, the velocity of the $i$ th particle is $v_{i}=\left(v_{i 1}, v_{i 2}, \ldots, v_{i n}\right)^{T}$, the best position of the $i$ th particle being searched is $P_{i}=\left(P_{i 1}, P_{i 2}, \ldots, P_{i n}\right)^{T}$, and the best position of the total particle swarm being searched is $P_{g}=$ $\left(P_{g 1}, P_{g 2}, \ldots, P_{g n}\right)^{T}$. Through some iterations, each particle updates its velocity and position based on the influence of its best position $P_{i}$ as well as the best position of the total particle swarm $P_{g}$. The iterative calculation is

$$
\begin{gathered}
v_{i d}^{k+1}=\omega v_{i d}^{k}+c_{1} \xi\left(p_{i d}^{k}-x_{i d}^{k}\right)+c_{2} \eta\left(p_{g d}^{k}-x_{g d}^{k}\right) \\
x_{i d}^{k+1}=x_{i d}^{k}+v_{i d}^{k+1},
\end{gathered}
$$

where $c_{1}, c_{2}$ are the learning factors, acceleration coefficients with positive values. They control the maximum step size the particle can achieve; $\omega$ is inertia weight; $\xi$ and $\eta$ are random numbers between 0 and $1 ; \xi, \eta \in \mathbf{U}[-1,1]$. Particle size $m$, inertia weight $\omega$, and maximum iteration number $K$ are considered as important factors in PSO. Inertia weight $\omega$ describes the influence of particle's previous generation velocity on the current generation. Controlling the value of $\omega$ can adjust the global and local searching capabilities of PSO algorithm. The larger is $\omega$, the better is the global searching capability, with a local searching capability being weaker. Contrarily, the local searching capability can be enhanced, while the global searching capability is weakened [22].

3.4.2. The Process of PSO Algorithm. Standard PSO algorithm procedures [23] are as follows.

Step 1. Initialize the particles $\mathbf{X}=\left(x_{1}, x_{2}, \ldots, x_{i}, \ldots, x_{m}\right)$, the best position of the $i$ th pariticle being searched is $P_{i}=\left(P_{i 1}, P_{i 2}, \ldots, P_{i n}\right)^{T}$, and the particles' velocities $v_{i}=$ $\left(v_{i 1}, v_{i 2}, \ldots, v_{i n}\right)^{T}$ randomly. Then set the acceleration coefficients $c_{1}$ and $c_{2}$, the maximum iteration number $K$, maximum velocity, and a maximum particle movement amplitude in order to decrease the cost of evaluation and to achieve a good convergence rate.

Step 2. Calculate the fitness value of each particle via the fitness function. There are many options when choosing a fitness function, but finding a good one often requires trial and error.

Step 3. Compare the particle's fitness value with the particle's best position $P_{i}$. If the current value is better than the previous best solution, replace it and set the current solution as the local best position $P_{i}$.

Step 4. Compare the individual particle's fitness with the population's global best position $P_{g}$. If the fitness of the current solution is better than the global best fitness, set the current solution as the new global best position $P_{g}$.

Step 5. Update the particles' positions and velocities by (2).

Step 6. Repeat Step 2 to Step 4 until a stopping criterion is satisfied or the iterations number $K$ is completed.

In this paper, we use real code to make neural network connection weights and threshold values expressed as particle parameters. The specific encode mode is as follows: let the number of input nodes be $m$, let the number of hidden nodes be $n$, and let the number of output nodes be $s$, with the individual string length of particle swarm being $L=n \times m+$ $s \times n+n+s$. Assume that the input layer and hidden layer connection weight matrix is

$$
\mathrm{IW}=\left[\begin{array}{cccc}
\mathrm{IW}_{11} & \mathrm{IW}_{12} & \cdots & \mathrm{IW}_{1 m} \\
\mathrm{IW}_{21} & \mathrm{IW}_{22} & \cdots & \mathrm{IW}_{2 m} \\
\vdots & \vdots & \ddots & \vdots \\
\mathrm{IW}_{n 1} & \mathrm{IW}_{n 2} & \cdots & \mathrm{IW}_{n m}
\end{array}\right]
$$


The threshold vector from the input layer to hidden layer is $B_{1}=\left[b_{11}, b_{12}, \ldots, b_{1 n}\right]^{T}$; then assume that the hidden layer and output layer connection weight matrix is

$$
\mathrm{LW}=\left[\begin{array}{cccc}
\mathrm{LW}_{11} & \mathrm{LW}_{12} & \cdots & \mathrm{LW}_{1 n} \\
\mathrm{LW}_{21} & \mathrm{LW}_{22} & \cdots & \mathrm{LW}_{2 n} \\
\vdots & \vdots & \ddots & \vdots \\
\mathrm{LW}_{s 1} & \mathrm{LW}_{s 2} & \cdots & \mathrm{LW}_{s n}
\end{array}\right]
$$

The threshold vector from the hidden layer to output layer is $B_{2}=\left[b_{21}, b_{22}, \ldots, b_{2 s}\right]^{T}$. So the particle's encoding is $X=$ $\left[\mathrm{IW}_{11} \cdots \mathrm{IW}_{n m} b_{21}, b_{22}, \ldots, b_{2 s}\right]$.

3.5. The Combination of PSO and RBF. As the PSO algorithm can easily fall into local optimum, it fails to achieve global optimum. The PSO algorithm is not theoretically rigorous proof of convergence to any type of functions' global extreme point; hence it may be difficult to obtain satisfactory results of complex test functions. When the PSO algorithm is running, if the parameter design of the algorithm or the selection of particles is in error, it will lead to a rapid disappearance of the diversity of particles, resulting in an algorithm "premature" phenomenon, further restricting the algorithm from converging to the global extreme point.

Meanwhile, the PSO algorithm's convergence speed is slow. In practical problems, it is necessary to reach the appropriate accuracy within a certain period of time, and it is not worth taking a long time to get feasible solution. This slow convergence speed is caused by the PSO using an individual optimum and the global optimum at each iteration.

Therefore, combining ANN and PSO will overcome their own shortcomings and achieve better prediction and optimization results. ANN and PSO are two different methods and have big difference in their information processing, and the complementariness between them is high. The two principal ways to combine them are (a) using PSO algorithm's global searching capability to optimize ANN's topology, connection weights and learning rules, improving the generalization capability and learning efficiency, which improve the ANN's global searching performance and (b) embedding ANN into the PSO algorithm and using ANN's good learning performance to enhance the performance of PSO optimization. In this study, we adopt the PSO algorithm to optimize the RBFNN's connection weights and thresholds, as revealed in Figure 5.

The procedures are as follows.

Step 1. Collect networking training specimens.

Step 2. Build the topology structure of RBFNN, that is, to determine the number of input, output, and hidden nodes.

Step 3. Initialize population.

Step 4. Calculate the fitness value of each particle.

Step 5. Compare the particle's fitness value with the particle's best position $P_{i}$. If the current value is better than the previous

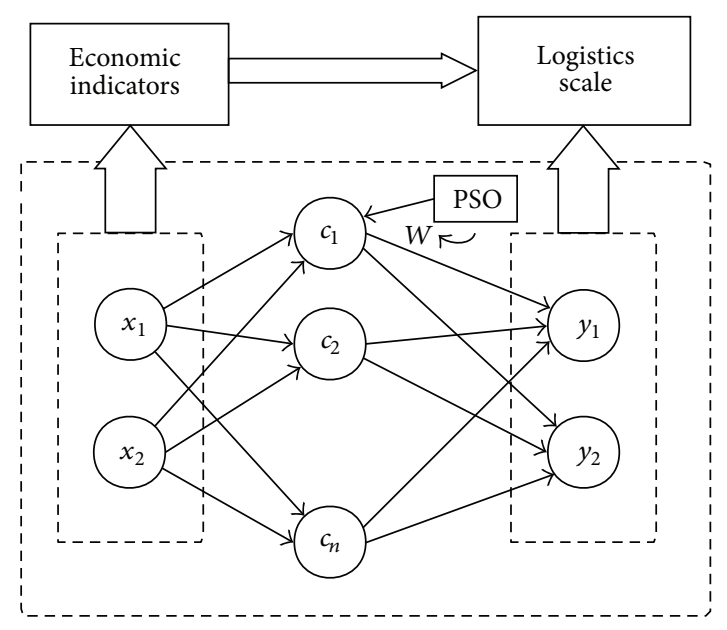

FIGURE 5: The physical model for the regional logistics demand.

best solution, replace it and set the current solution as the local best position $P_{i}$.

Step 6. Compare the individual particle's fitness with the population's global best position $P_{g}$. If the fitness of the current solution is better than the global best fitness, set the current solution as the new global best position $P_{g}$.

Step 7. Update the particles' positions and velocities by (2).

Step 8. Repeat Step 4 to Step 6 until a stopping criterion is satisfied or the iterations number $K$ is completed.

Step 9. Decode the population's global best position. The optimized values are RBFNN's connection weights and threshold values. Then train the RBFNN.

The algorithm flowchart is shown in Figure 6.

\section{Case Study}

4.1. Data Processing. In this section, the proposed PSORBFNN model will be applied to predict regional logistics demand in Sichuan province, China. The data are selected from the Sichuan Province Statistical Yearbook from 1994 to 2008, as exhibited in Table 4.

Before using these indicators, the correlation between regional economic indicators and logistics demand indicators should be verified. The verification result of the correlation is indicated in Table 5.

From Table 5, all the correlation coefficients are close to 1 , and correlation is significant at the 0.01 level (2-tailed). Accordingly, the logistics scale indicators, that is, total freight traffic $\left(y_{1}\right)$, freight turnover $\left(y_{2}\right)$, and regional economic indicators, namely, gross domestic product $\left(x_{1}\right)$, primary industry output value $\left(x_{2}\right)$, secondary industry output value $\left(x_{3}\right)$, tertiary industry output value $\left(x_{4}\right)$, regional retail sales $\left(x_{5}\right)$, total import and export $\left(x_{6}\right)$, and per capita consumption $\left(x_{7}\right)$, have high correlation. These indicators are valid as inputs and outputs of the PSO-RBFNN. 


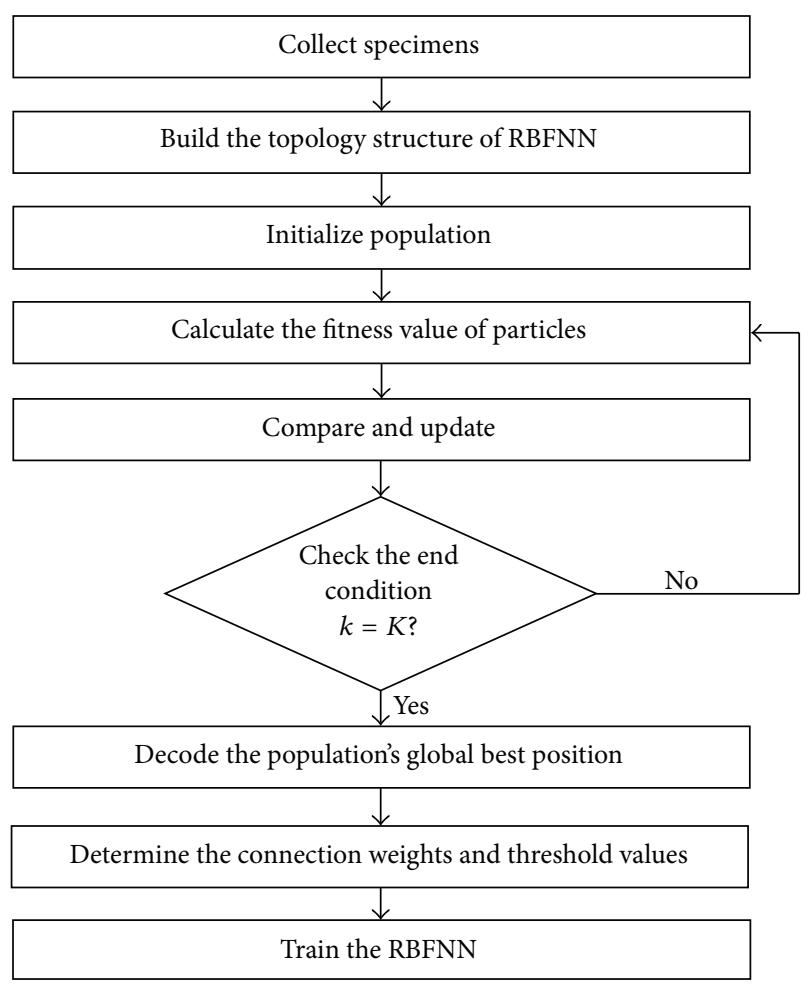

FIGURE 6: The algorithm flowchart.

As the selected indicators have different attributes and dimensions, the input and output data should be preprocessed to accelerate the network's training speed and convergence and improve the prediction accuracy of PSO-RBFNN. In this paper, we adopt normalization processing:

$$
X_{i}=\frac{X-X_{\min }}{X_{\max }-X_{\min }},
$$

where $X_{i}$ is the normalized data, $X$ is the sample value, and $X_{\max }$ and $X_{\min }$ are the maximum and minimum sample values. For the output of the network, the reverse normalization formula is $X=X_{\min }+\left(X_{\max }-X_{\min }\right) \times X_{i}$.

After the normalization processing, the input data is shown in Table 6. Each row has at least one 0 and one 1. For the S-shaped curve, the training effect will be worse, training times will increase, and it may not be able to reach the expected target.

To avoid the extreme data 0 and 1 disrupting prediction result, we set the maximum normalized value as 0.9999 and the minimum normalized value as 0.0001 .

4.2. The PSO-RBFNN Training. On the determination of nodes in the hidden layer, there is no uniform standard. Consequently, we use a trial-and-error method based on empirical principles: let $m$ be the number of input nodes, let $n$ be the number of output nodes, and let $k$ be the number of hidden nodes; therefore (a) $k=\sqrt{m+n}+a$, where $a$ is a constant between 1 and 10; (b) $k=m \times(n+1)$; (c) $k=\sqrt{m \times n}$; (d) $k=\log _{2} m ;$ (e) $k=2 \times(m+n) / 3$; and (f) $k=2 n+1$. The network training starts from

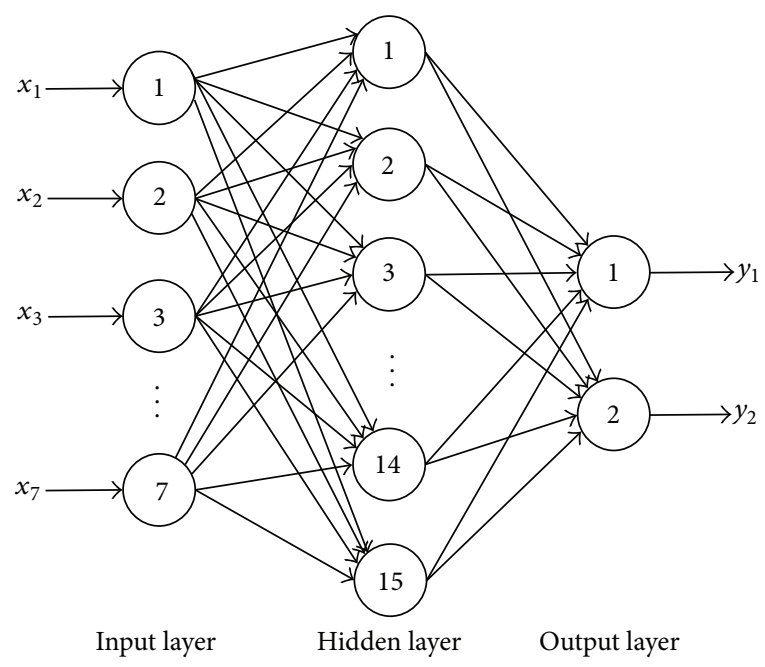

FIGURE 7: The PSO-RBFNN model structure.

a smaller number of hidden nodes. If the training is done too many times or does not reach the specified training times, or the network does not converge to a predetermined accuracy, the training process should be interrupted. The number of hidden nodes is gradually increased. The model is retrained, until a satisfactory training effect is achieved. In this way, the number of hidden nodes is ultimately determined as 15 . According to the index system we built, the numbers of input and output nodes are determined as 7 and 2. Therefore, the PSO-RBFNN node configuration form can be identified as 715-2. The topology is demonstrated in Figure 7.

To determine the PSO-RBFNN learning factors, we have a parametric test of the learning factors $c_{1}$ and $c_{2}$ in this study. The results are demonstrated in Table 7 . Additionally, $c_{1}=1.5$ and $c_{2}=0.2$ are determined because of the lowest training error 0.001291 .

In order to train the PSO-RBFNN, we chose data from the 1994 2004 yearbooks as network training specimens. The PSO parameters are determined: $\omega_{\max }=0.9, \omega_{\min }=0.4$, $x_{\min }=-10, x_{\max }=10$, and $v_{\max }=8$. Then we can determine the connection weights and thresholds, train the RBFNN, and use it to predict the logistics demand of Sichuan province in 2010 2015.

The transfer function of hidden layer utilizes $S$ type tangent function: $f(x)=\left(1-e^{-x}\right) /\left(1+e^{-x}\right)$, mapping from domain $(-\infty,+\infty)$ to range $(-1,1)$. The output layer transfer function uses linear function: $f(x)=x$. The training specimens and transfer function are shown in Figure 8.

\section{Analysis of Result}

5.1. The Model Evaluation. After training, we test the PSORBFNN model's fitness and prediction capability. Fitness test uses the model to fit to historical data and to estimate the preprediction error. Extrapolation test utilizes postprediction error to estimate the preprediction error. In the actual prediction, historical data are divided into two groups with most of the data being a sample to build the predictive model 
TABLE 4: The logistics demand indicators and regional economic indicators statistical data.

\begin{tabular}{lccccccccc}
\hline Year & $x_{1}$ & $x_{2}$ & $x_{3}$ & $x_{4}$ & $x_{5}$ & $x_{6}$ & $x_{7}$ & $y_{1}$ & $y_{2}$ \\
\hline 1994 & 200.141 & 59.737 & 78.277 & 62.127 & 72474.08 & 2916.45 & 1367.17 & 723.36 & 497 \\
1995 & 244.321 & 66.246 & 98.091 & 79.984 & 93636.51 & 2358.72 & 1646.27 & 671.54 & 565 \\
1996 & 287.165 & 77.002 & 115.601 & 94.562 & 109144.85 & 2148.83 & 1879.6 & 520.04 & 536 \\
1997 & 324.147 & 88.028 & 126.532 & 109.587 & 121236.99 & 1790.05 & 2077.74 & 569.35 & 549 \\
1998 & 347.409 & 91.224 & 132.401 & 123.784 & 129856.95 & 2093.28 & 2243.41 & 507.59 & 568 \\
1999 & 364.912 & 92.603 & 134.963 & 137.346 & 138258.69 & 2470.69 & 2347.53 & 501.42 & 574 \\
2000 & 392.82 & 94.558 & 143.311 & 154.951 & 152374.90 & 2545.17 & 2550.48 & 549.43 & 597 \\
2001 & 429.35 & 98.168 & 157.201 & 173.981 & 168040.41 & 3099.16 & 2707.15 & 541.41 & 648 \\
2002 & 472.501 & 104.795 & 173.338 & 194.368 & 185005.76 & 4469.19 & 2914.39 & 572.97 & 704 \\
2003 & 533.309 & 112.861 & 201.48 & 218.968 & 209105.43 & 4469.19 & 3203.36 & 572.00 & 699 \\
2004 & 637.963 & 137.992 & 249.317 & 250.654 & 238395.15 & 5638.62 & 3656.2 & 655.80 & 804 \\
2005 & 738.511 & 148.114 & 306.723 & 283.674 & 298137.34 & 6871.62 & 4130.08 & 703.64 & 898 \\
2006 & 863.781 & 160.348 & 377.519 & 323.914 & 342164.83 & 7904.76 & 4501.34 & 742.00 & 891 \\
2007 & 1030.530 & 203.200 & 464.130 & 383.200 & 401557.46 & 11020.97 & 5259.22 & 799.40 & 979 \\
2008 & 1260.123 & 221.615 & 582.339 & 456.169 & 480076.38 & 14384.61 & 6072.00 & 1145.13 & 1513 \\
2009 & 1415.136 & 223.591 & 670.774 & 520.770 & 527835.10 & 24227.28 & 6817.42 & 1026.35 & 1913 \\
\hline
\end{tabular}

TABLE 5: The correlation between indicators.

\begin{tabular}{cccccccc}
\hline & $x_{1}$ & $x_{2}$ & $x_{3}$ & $x_{4}$ & $x_{5}$ & $x_{6}$ \\
\hline$y_{1}$ & $0.867^{* *}$ & $0.826^{* *}$ & $0.892^{* *}$ & $0.838^{* *}$ & $0.859^{* *}$ & $0.921^{* *}$ & $0.835^{* *}$ \\
$y_{2}$ & $0.951^{* *}$ & $0.906^{* *}$ & $0.961^{* *}$ & $0.939^{* *}$ & $0.939^{* *}$ & $0.985^{* *}$ & $0.938^{* *}$ \\
\hline
\end{tabular}

${ }^{* *}$ Correlation is significant at the 0.01 level (2-tailed).

TABLE 6: The normalized data.

\begin{tabular}{cccccccccc}
\hline Year & $x_{1}$ & $x_{2}$ & $x_{3}$ & $x_{4}$ & $x_{5}$ & $x_{6}$ & $x_{7}$ & $y_{1}$ \\
\hline 1994 & 0.0001 & 0.0001 & 0.0001 & 0.0001 & 0.0001 & 0.0502 & 0.0001 & 0.4228 & 0.0001 \\
1995 & 0.0364 & 0.0397 & 0.9154 & 0.0389 & 0.0404 & 0.0253 & 0.0512 & 0.3241 & 0.0480 \\
1996 & 0.0716 & 0.1054 & 0.6798 & 0.0707 & 0.0747 & 0.0160 & 0.0940 & 0.0355 & 0.0275 \\
1997 & 0.1021 & 0.1727 & 0.5911 & 0.1035 & 0.1014 & 0.0000 & 0.1304 & 0.1294 & 0.0367 \\
1998 & 0.1212 & 0.1922 & 0.6308 & 0.1344 & 0.1205 & 0.0135 & 0.1608 & 0.0118 & 0.0501 \\
1999 & 0.1356 & 0.2006 & 0.6761 & 0.1640 & 0.1390 & 0.0303 & 0.1799 & 0.0001 & 0.0544 \\
2000 & 0.1586 & 0.2125 & 0.7462 & 0.2024 & 0.1702 & 0.0337 & 0.2171 & 0.0915 \\
2001 & 0.1887 & 0.2345 & 0.8043 & 0.2439 & 0.2049 & 0.0583 & 0.2459 & 0.0762 \\
2002 & 0.2242 & 0.2750 & 0.8152 & 0.2883 & 0.2423 & 0.1194 & 0.2839 & 0.1363 & 0.1066 \\
2003 & 0.2742 & 0.3242 & 0.8458 & 0.3420 & 0.2956 & 0.1194 & 0.3369 & 0.1345 & 0.1462 \\
2004 & 0.3603 & 0.4776 & 0.7545 & 0.4111 & 0.3603 & 0.1715 & 0.4200 & 0.2941 & 0.2168 \\
2005 & 0.4431 & 0.5394 & 0.8215 & 0.4830 & 0.4924 & 0.2265 & 0.5069 & 0.3852 & 0.2832 \\
2006 & 0.5462 & 0.6140 & 0.8896 & 0.5708 & 0.5897 & 0.2725 & 0.5751 & 0.4583 & 0.2782 \\
2007 & 0.6835 & 0.8756 & 0.7806 & 0.7000 & 0.7209 & 0.4114 & 0.7141 & 0.5677 & 0.3404 \\
2008 & 0.8724 & 0.9879 & 0.8831 & 0.8591 & 0.8945 & 0.9058 & 0.8632 & 0.8453 & 0.7175 \\
2009 & 0.9999 & 0.9999 & 0.9999 & 0.9999 & 0.9999 & 0.9999 & 0.9999 & 0.9999 & 0.9999 \\
\hline
\end{tabular}

and the other small parts of the data being used for the extrapolation test.

The data collected from the 1994 2004 yearbooks are selected as fitness test specimens. The fitness error is under $9 \times 10^{-12}$; hence the PSO-RBFNN model fits well with historical data from 1994 to 2004. The data during 2005 2009 are chosen as extrapolation test specimens. In this paper, the extrapolation test utilizes mean absolute percent error (MAPE) as an error indicator. The formula is

$$
\operatorname{MAPE}=\frac{1}{n} \sum_{i=1}^{n}\left(\frac{\left|x_{i}-\widehat{x}_{i}\right|}{x_{i}} \times 100 \%\right)
$$


TABLE 7: The normalized data.

\begin{tabular}{cccccc}
\hline$c_{1}$ & $c_{2}$ & $\begin{array}{c}\text { Training } \\
\text { error }\end{array}$ & $c_{1}$ & $c_{2}$ & $\begin{array}{c}\text { Training } \\
\text { error }\end{array}$ \\
\hline \multirow{4}{*}{4} & 0.7 & 0.014683 & & 0.7 & 0.002705 \\
& 0.5 & 0.008015 & 1.7 & 0.5 & 0.003474 \\
& 0.4 & 0.011149 & & 0.4 & 0.003087 \\
& 0.2 & 0.008810 & & 0.2 & 0.001945 \\
\hline \multirow{3}{*}{3} & 0.7 & 0.002918 & & 0.7 & 0.002310 \\
& 0.5 & 0.03043 & & 0.5 & 0.003224 \\
& 0.4 & 0.019198 & & 0.4 & 0.003011 \\
& 0.2 & 0.003097 & & $\mathbf{0 . 2}$ & 0.001291 \\
\hline \multirow{3}{*}{2} & 0.7 & 0.002679 & & 0.7 & 0.003241 \\
& 0.5 & 0.002578 & & 0.5 & 0.002053 \\
& 0.4 & 0.003098 & & 0.4 & 0.002703 \\
& 0.2 & 0.002796 & & 0.2 & 0.003204 \\
\hline
\end{tabular}
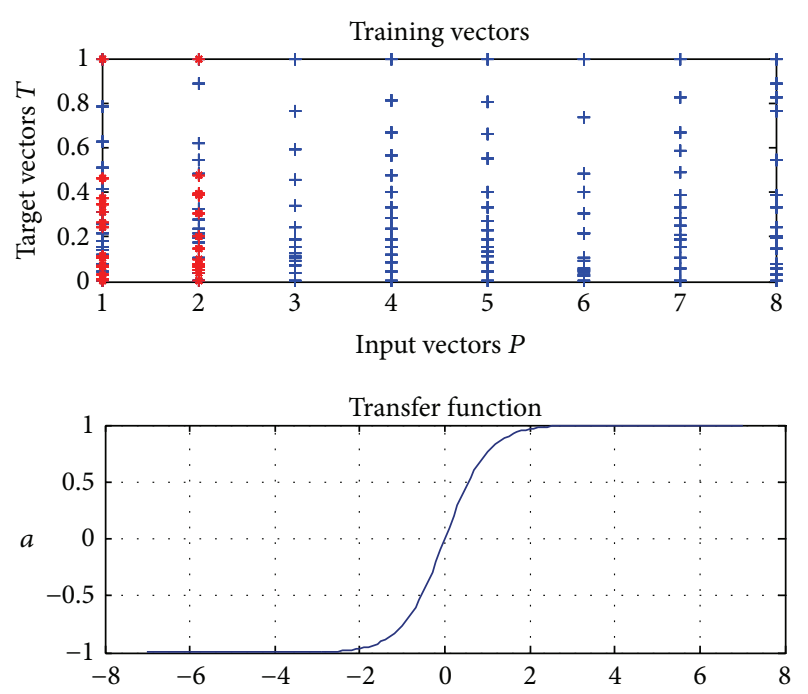

FIGURE 8: Training vectors and transfer function.

Various prediction models' capability can be measured by MAPE and the range of MAPE. The prediction accuracy is shown in Table 8. Referring to (6), we can calculate MAPE = $2.7 \%$, which is under $10 \%$. According to Table 8, this PSORBFNN has a good fitness capability and extensionality. The fitness error and prediction error are illustrated in Figure 9.

To prove the PSO-RBFNN's good prediction capability, we compare the prediction capability among PSO-RBFNN, a regular BP (backpropagation) network, and a regular RBFNN model. All the inputs and outputs are the same in each model. The prediction errors are shown in Figure 10. Compared with the BP network and the regular RBFNN model, the PSORBFNN has smaller errors as well as a better convergence and convergence rate. The training performance of the two different RBFNNs is shown in Figure 11. The training performance of PSO-RBFNN is 0.00125095 , less than the training performance of the regular RBFNN 0.00147074. Accordingly, the PSO-RBFNN has a better prediction capability and convergence.
TABLE 8: The MAPE range and prediction evaluation.

\begin{tabular}{lc}
\hline MAPE range & Prediction evaluation \\
\hline MAPE $\leq 10 \%$ & Precision prediction \\
$10 \% \leq$ MAPE $\leq 20 \%$ & Good prediction \\
$20 \% \leq$ MAPE $\leq 50 \%$ & Feasible prediction \\
MAPE $>50 \%$ & Error prediction \\
\hline
\end{tabular}

5.2. Prediction Result. For the purpose of predicting the regional logistics demands in 2010 2015, it is necessary to input the economic indicators of Sichuan in 2010 2015. In the recent years, the economic development of Sichuan province has grown rapidly with the average GDP annual growth rate of $13.93 \%$ from 1994 to 2009 . Hence, it is assumed that the average annual growth rate in the next few years will be $13.93 \%$. 2011 was the first year of the "Twelfth Five-Year Program" in China. During the period of the "Twelfth FiveYear Program," the industrial structure in China will adjust further, and it is expected that the tertiary industry annual growth rate in Sichuan province will increase by $15.23 \%$ as acceptable with the Delphi method. In 1994 2009, the average annual growth rate of the total consumer goods retail sales was $13.86 \%$, and the consumption growth rate was $11.53 \%$. Therefore, in the same assumption, the total retail sales of consumer goods and consumption will have the same growth trend from 2010 to 2015. The foreign trade average annual growth rate from 1994 to 2007 in Sichuan province was $15.16 \%$; hence we assume that foreign trade will maintain such a growth rate.

The prediction outcomes for the Sichuan province regional economy are illustrated in Table 9. The prediction results in Table 10 show that the total freight traffic and freight turnover are expected to grow faster.

According to Tables 9 and 10, the economic indicators and the scale of logistics demand in Sichuan province reveal a rapid growth trend in the next five years and also prove the inherent relevance between regional logistics demand and regional economy.

In particular, the "5.12 Wenchuan Earthquake" inflicted heavy loss on Sichuan province. Hence, after the reconstruction process is completed, logistics demand is expected to increase sharply with the result that the regional logistics industry will be highlighted in the growth of the regional economy. Further, as "The 12th Five-Year Program on National Economic and Social Development" proposes, industrial optimization will be China's top priority. To achieve this optimization, China will need to speed up the development of the modern service industry, in which the logistics industry is the principal development focus.

\section{Conclusion and Discussion}

Logistics is a pioneer in the development of logistics demand. During the process of conducting logistics development planning, regional planners' lack of correct understanding of the logistics demand will result in the imbalance between supply and demand. Furthermore, it will cause the phenomenon of 

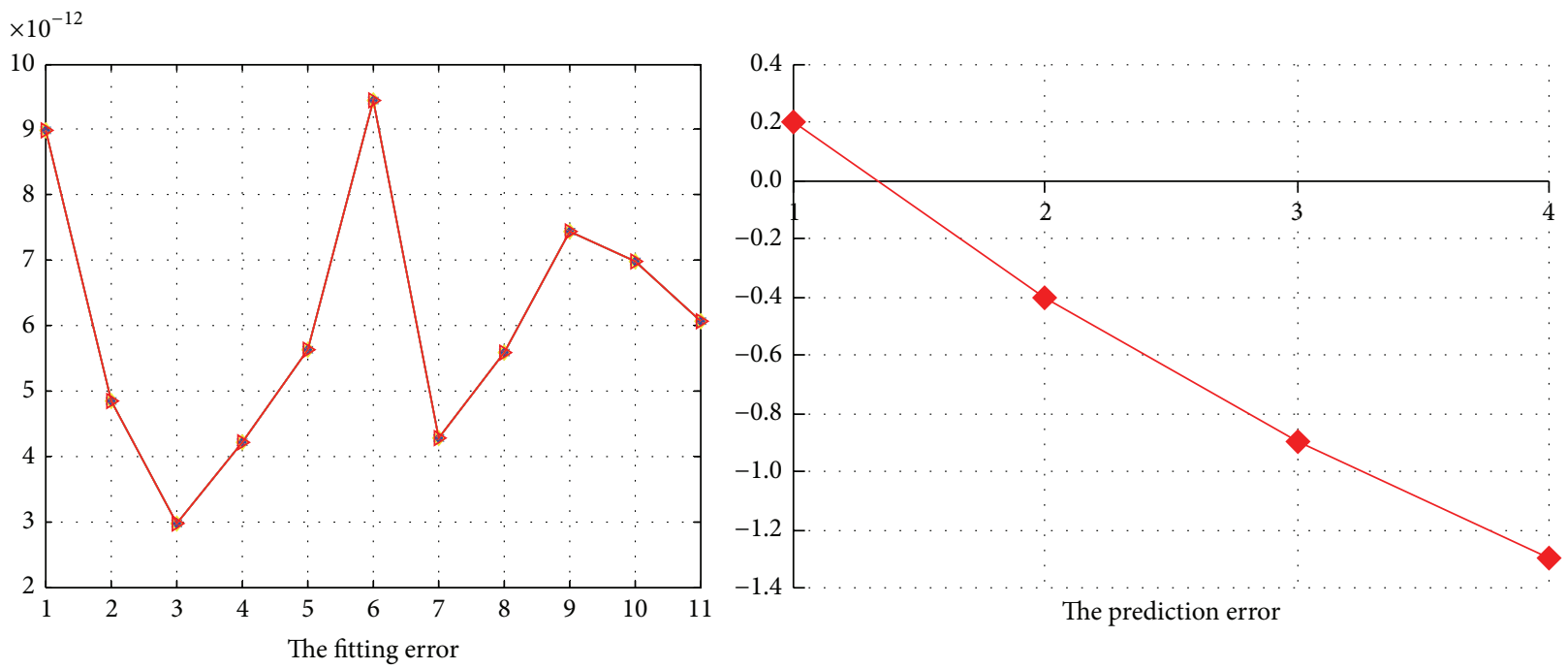

FIGURE 9: The fitting and predicting error.

TABLE 9: 2010 2015 economic indicators prediction.

\begin{tabular}{cccccccc}
\hline Year & GDP & PIO & SIO & TIO & RRS & TIE & PCC \\
\hline 2010 & 1612.237 & 244.157 & 774.057 & 600.072 & 600980.67 & 27899.82 \\
2011 & 1836.791 & 266.614 & 893.241 & 691.451 & 684262.49 & 32129.06 & 8448.22 \\
2012 & 2092.621 & 291.137 & 1030.778 & 796.745 & 779085.23 & 36999.40 \\
2013 & 2384.083 & 317.916 & 1189.491 & 918.072 & 887048.17 & 42608.02 & 9401.12 \\
2014 & 2716.140 & 347.157 & 1372.642 & 1057.875 & 1009972.24 & 49066.83 & 11647.14 \\
2015 & 3094.447 & 379.088 & 1583.994 & 1218.968 & 1149930.71 & 56504.72 & 12964.00 \\
\hline
\end{tabular}

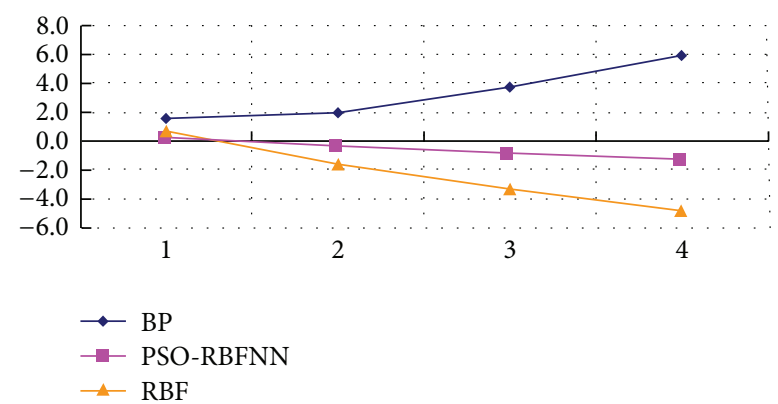

FIGURE 10: The prediction errors in different models.

insufficient supply and overinvestment. It will also hinder the development of the logistics industry. Therefore, studying the forecast of regional logistics demand has vital practical significance. In this paper, based on the theory of regional logistics demand and its prediction, the characteristics and the main content of regional logistics demand prediction are analyzed; the PSO-RBFNN prediction model is built; and an empirical research of logistics demand in Sichuan province is conducted. The principal conclusions are as follows.

(1) By feasibility analysis and empirical research, it is proved that a PSO-RBFNN model, which introduces a PSO algorithm to optimizing the RBF neural network connecting weights and thresholds, is scientific and practical. Combining RBFNN with PSO overcomes their own shortcomings and achieves better prediction and optimization results. (2) Through correlation analysis, the strong correlation between the regional economy and regional logistics demand is proven. The rapid development of the regional economy will drive the rapid development of regional logistics. (3) In the empirical research, we applied the PSO-RBFNN model to predict the regional logistics demand of Sichuan province from 2010 to 2015. After inputting the regional logistics demand prediction indicators values into the PSO-RBFNN model, valid results are calculated in Table 9, suggesting that the total freight traffic and freight turnover will increase by $13.7 \%$ and $58.8 \%$, respectively. The PSO-RBFNN model is utilized to fit well the nonlinear relationship between the regional economy and regional logistics demand. (4) Through empirical research, it is obvious that using logistics demand and regional economic indicators to predict regional 

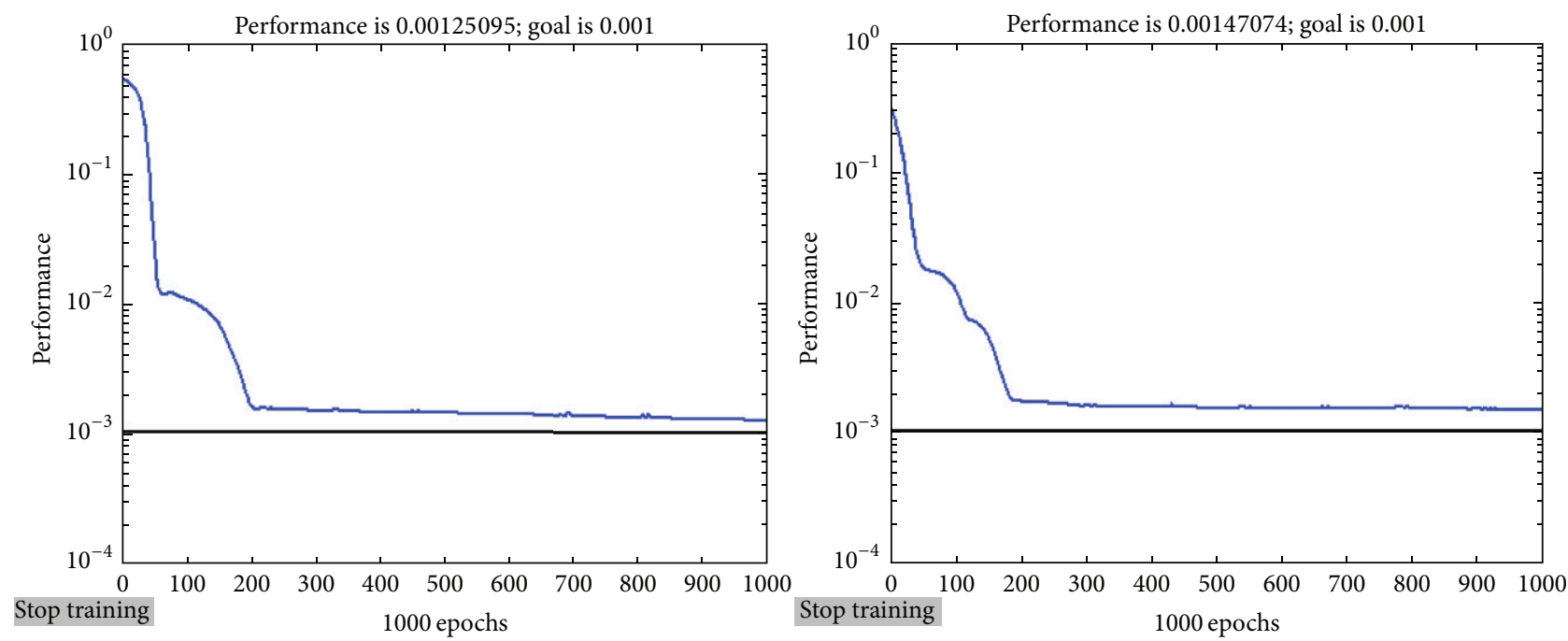

FIGURE 11: The training errors in different RBFNNs.

TABLE 10: Total freight traffic and freight turnover prediction results.

\begin{tabular}{lcccccc}
\hline Year & 2010 & 2011 & 2012 & 2013 & 2014 & 2015 \\
\hline TFT $(10000$ tons) & 104337 & 108129 & 110364 & 114438 & 115782 & 118621 \\
FT (billion ton-km) & 2077 & 2320 & 2514 & 2796 & 3013 & 3298 \\
\hline
\end{tabular}

logistics demand is a viable research method. Multiple factors affect the demand for logistics. Studying the development of logistics demand based on the trend of only one indicator is unreasonable. On the other hand, compared with the traditional forecasting methods, the PSO-RBFNN model predicts regional logistics demand more accurately.

Nevertheless, our study should be improved in terms of the index system of regional logistics demand prediction. It is not enough to establish indicators only based on the perspective of economic indicators and freight volume, even though these indicators are easy to be collected. Other indicators such as logistics cost GDP ratio should also be studied. Further, we predict the scale of regional logistics demand, rather than the structure and quality of regional logistics demand. In future research, the structure and quality of regional logistics demand will be investigated.

\section{Conflict of Interests}

The authors declare that there is no conflict of interests regarding the publication of this paper.

\section{Acknowledgments}

This work is supported by the National Natural Science Foundation of China (Grant no. 71301109), the Western and Frontier Region Project of Humanity and Social Sciences Research, Ministry of Education of China (Grant no.
13XJC630018), and the Initial Funding for Young Teachers of Sichuan University (Grant no. 2013SCU11014).

\section{References}

[1] R. Godrigo and H. Mahmassani, "Forecasting freight transportation demand with the space-time multinomial probit model," Transportation Research Part B: Methodological, vol. 34, no. 5, pp. 403-418, 2000.

[2] B. Adrangi, A. Chatrath, and K. Raffiee, "The demand for US air transport services: a chaos and nonlinearity investigation," Transportation Research Part E: Logistics and Transportation Review, vol. 37, no. 5, pp. 337-353, 2001.

[3] J. T. Fite, G. D. Taylor, J. S. Usher, J. R. English, and J. N. Roberts, "Forecasting freight demand using economic indices," International Journal of Physical Distribution \& Logistics Management, vol. 32, no. 4, pp. 299-308, 2002.

[4] X. Guo, S. Xie, and B. Hu, "Regional logistics demand analysis model and solution," Journal of Southeast University (Natural Science), vol. 31, no. 3, pp. 1-5, 2001.

[5] R. Wang, C. Chen, and V. Berkhard, "Theories and methodology on long term projection of cargo flows in Tumen River economic developmen area," Human Geography, vol. 9, pp. 2125, 1999.

[6] Y. Lai, Q. Zheng, S. Zhang, and C. Ji, "Application of gray forecast model to transport volume in Jinsha River," Journal of Wuhan University of Hydraulic and Electric Engineering, vol. 33, no. 1, pp. 96-99, 2000.

[7] Y. Zhang, H. Ye, M. Ren, and C. Ji, "Application of gray forecast using neural network model," Southeast Jiaotong University, vol. 34, no. 5, pp. 602-605, 1999. 
[8] H. Niu and Y. Yin, "Fuzzy forecasting on freight demands in railroad hub," Journal of Lanzhou Railway University, vol. 17, no. 3, pp. 89-94, 1998.

[9] R. Garrido and H. Mahmassani, "Forecasting freight transportation demand with the space-time multinomial probit model," Transportation Research Part B: Methodological, vol. 34, no. 5, pp. 403-418, 2000.

[10] Q. Sun and H. Ding, "Theory and model establishment for regional logistics demand prediction," Theoretical Discussion, no. 10, pp. 27-30, 2004.

[11] L. Chu, Z. Tian, and X. Xie, "Application of an combination forecasting model in logistics demand," Journal of Dalian Maritime University, vol. 30, no. 4, pp. 43-46, 2004.

[12] J. Sun and X. Xiang, "Logistics demand prediction research based on the gray linear regression combination model," Industrial Technology \& Economy, vol. 26, no. 10, pp. 146-148, 2007.

[13] Q. Dong, "Regional logistics information platform and resource planning," Traffic and Transportation Engineering, no. 4, pp. 56$58,2002$.

[14] J. Xiao, "Development of urban centers and modern logistics industry," Commodity Storage and Conservation, vol. 5, pp. 710, 2002.

[15] X. Heng, "Reflections on the development of logistics enterprises in China," Containerization, vol. 5, pp. 21-22, 2003.

[16] Q. Zhang, "United States, Japan logistics," Modern Enterprise Education, no. 4, pp. 18-19, 2003.

[17] J. Moody and C. Darken, "Fast learning in networks of locallytuned processing units," Neural Computation, vol. 1, no. 2, pp. 281-294, 1989.

[18] S. Haykin, Neural Networks and Learning Machines, Prentice Hall, 2008.

[19] J. Kennedy and R. Eberhart, "Particle swarm optimization," in Proceedings of the IEEE International Conference on Neural Networks, pp. 1942-1948, December 1995.

[20] E. Assareh, M. A. Behrang, M. R. Assari, and A. Ghanbarzadeh, "Application of PSO (particle swarm optimization) and GA (genetic algorithm) techniques on demand estimation of oil in Iran," Energy, vol. 35, no. 12, pp. 5223-5229, 2010.

[21] P. Wang, Z.-Y. Huang, M.-Y. Zhang, and X.-W. Zhao, "Mechanical property prediction of strip model based on PSO-BP neural network," Journal of Iron and Steel Research International, vol. 15 , no. 3, pp. 87-91, 2008.

[22] Z. Ji, H. Liao, and Q. Wu, Particle Swarm Optimization and Its Application, Science Press, Beijing, China, 2009.

[23] Y. Shi and R. Eberhart, "A modified particle swarm optimizer," in Proceedings of the IEEE International Conference on Evolutionary Computation (ICEC '98), pp. 69-73, IEEE, Anchorage, Alaska, USA, May 1998.

[24] R. Yang, H. Zhang, and Z. Miao, "Moving average method in logistics forecasting techniques," Journal of Wuhan University of Technology, vol. 25, no. 3, pp. 353-355, 2001.

[25] H. Widiarta, S. Viswanathan, and R. Piplani, "On the effectiveness of top-down strategy for forecasting autoregressive demands," Naval Research Logistics, vol. 54, no. 2, pp. 176-188, 2007.

[26] X. Qiao, M. Dong, and M. Zhang, "Prediction of passenger and cargo traffic of National Highway based on elastic coefficient method," East China Highway, no. 5, pp. 87-90, 2004. 


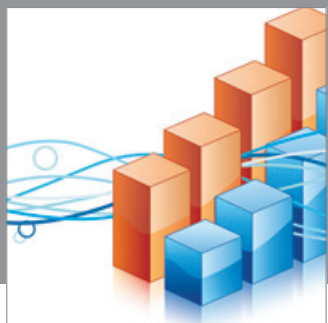

Advances in

Operations Research

mansans

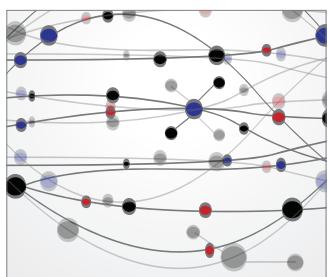

The Scientific World Journal
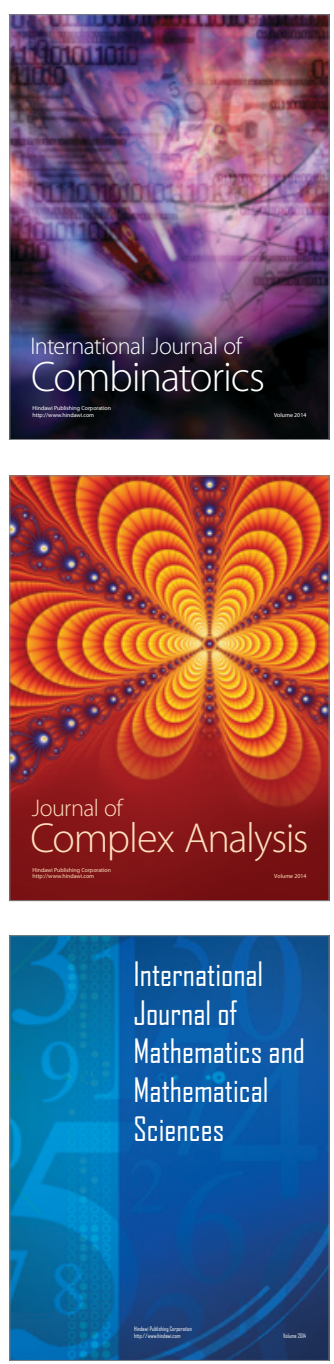
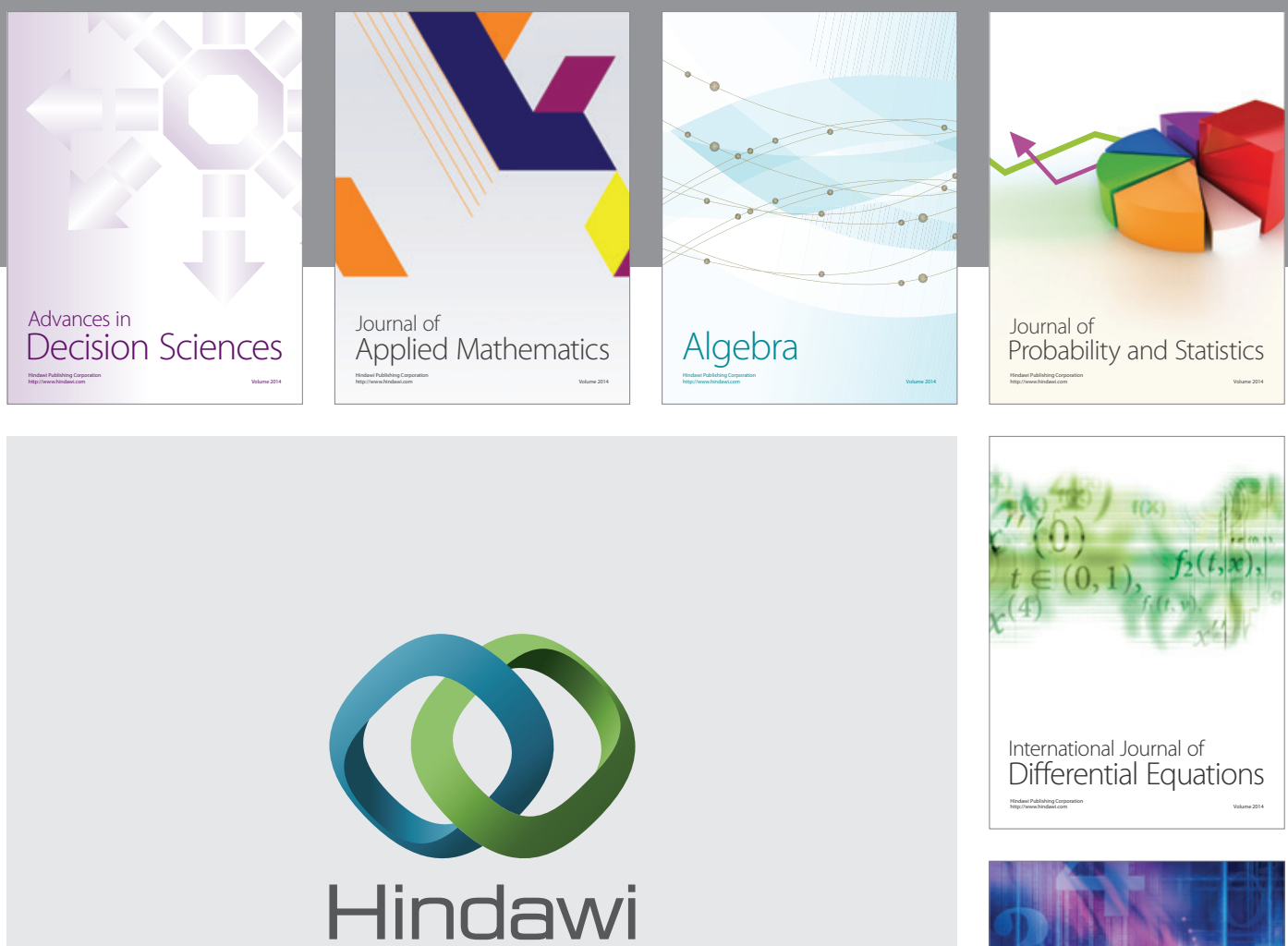

Submit your manuscripts at http://www.hindawi.com
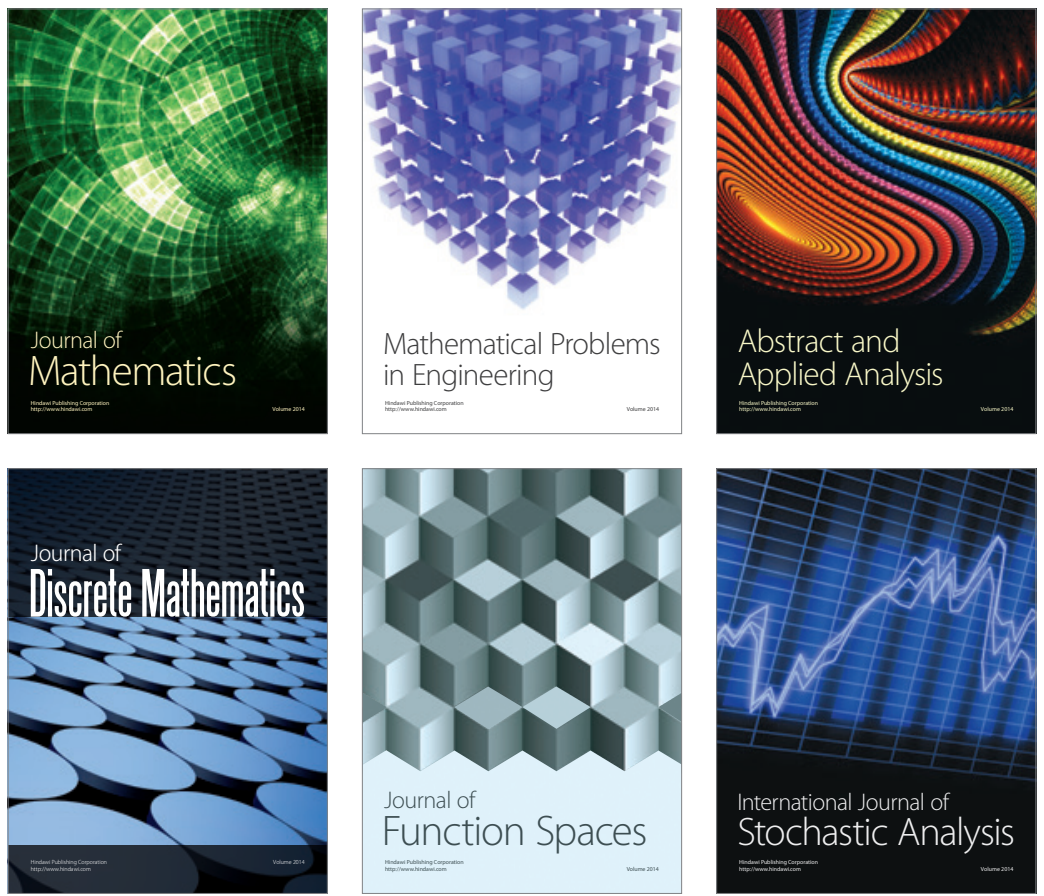

Journal of

Function Spaces

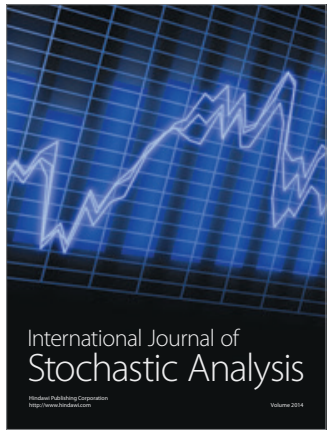

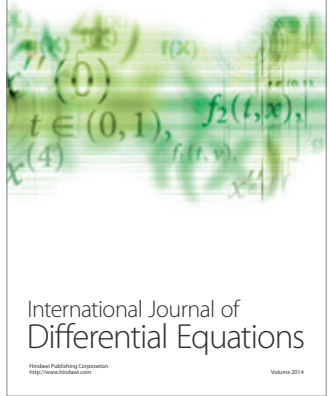
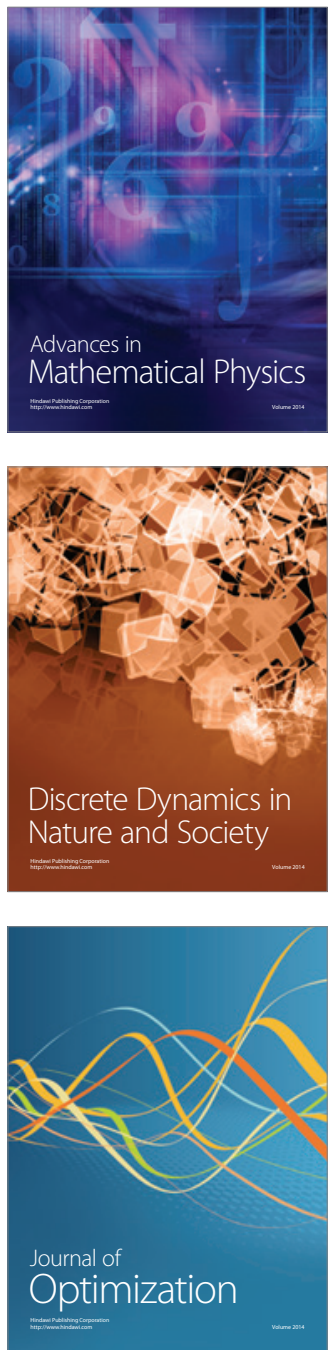